\title{
The Study on the effect of wave load on the ship hull deformation
}

\author{
Wang Yanwen ${ }^{1, a}$, Chen Jiahui ${ }^{1, b}$, Gai shan ${ }^{1, c}$ \\ 1 Wuhan University of Technology, Wuhan, China \\ a'wangyanwenwhut@163.com, bcjh123@163.com, cgaishan@163.com
}

\begin{abstract}
Keywords: wave load; wave phase; hull deformation; bearing displacement
Abstract. In order to avoid the impact of hull deformation on the shaft and other ship machinery, it is necessary to study the deformation of the ship under wave load. Firstly, The paper uses ANSYS element software dividing mesh of the whole ship, and then the APDL is used to calculate the dynamic pressure of wave. The results show that: under the same conditions, the hull with different deformation to the different phase of the waves, hull deformation showed a sinusoidal curve along with the movement of wave phase, with respect to $4 \mathrm{~m}$ wave height, the shafting is obviously raised under $6 \mathrm{~m}$ wave heights, but with smaller fluctuations in movement wave. Therefore, hull deformation is not the same under the different wave loading, hull deformation data can be the analysis conditions of shafting in different conditions of sea, and to analyze the effect of wave loads for other marine machinery.
\end{abstract}

\section{Introduction}

With the evolution of the background of the times, ships are becoming larger and high power, the rigidity of the shafting system also been increased[1,2], but the rigidity of the hull is relatively smaller, so the effects of hull deformation of ship for the shafting system can not be ignored, each bearing position will be changed because of the hull deformation, resulting in ship shafting work changed, endanger the safety of ship navigation, especially the kind ships of thick short tail shaft, such as large bulk carriers and tankers, the rigidity of ship shafting is relatively large, the deformation of the hull be sensitive. Therefore, the study of ship deformation under wave loads is very important.

Zhu Junshao et al conclude the hull deformation measurement technique [3,4], but this work too laborious,so theoretical calculation method is paid more attention by scholars, the finite element method and the ship beam theory is the main theoretical source of calculation of hull deformation. By the theory of ship hull girder, Li Jiaqi calculated the deformation of the hull, but it is proved that the results and the actual comparison has a large deviation.

This paper is mainly based on a container ship, using the finite element programming method and APDL language loading procedure to apply load on ship automatically,using the handle boundary conditions of inertia release to derive the hull deformation under the different conditions, according to the situation of the hull deformation to calculate the change of vibration of shafting. The results show that useing this method to estimate the deformation of ship hull, and the results are compared with the actual deformation. The error is very small.

\section{Calculation Model}

This study is mainly based on a 8530TEU container ship, the main structure parameters: length between perpendiculars $320.00 \mathrm{~m}$, wide $42.80 \mathrm{~m}$, deep $24.80 \mathrm{~m}$, design draft $14.65 \mathrm{~m}$, displacement 137253t. Using ANSYS finite element analysis software to establish 8530TEU container ship finite element model, mainly adopts shell 163 and the beam 188 elements to simulate the girder structure of hull. The model includes 95728 unit and 918481 nodes,model as shown in Figure 1. 


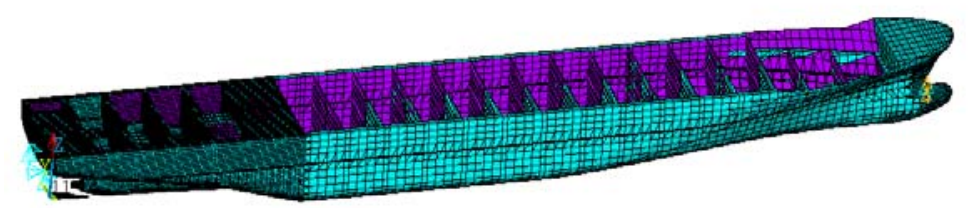

Fig. 1 finite element model of ship

\section{2 calculation method}

\subsection{The calculation regular wave load}

The calculation of regular wave has the following three prerequisites:

(1) the fluid is considered as an ideal condition, ignoring viscosity and compressibility;

(2) the motion of fluid particles is treated as a potential flow without rotation;

(3) The relative height is very small in the condition of micro wave amplitude.

The motion of regular waves and the model of calculation parameters as shown in Figure 2.

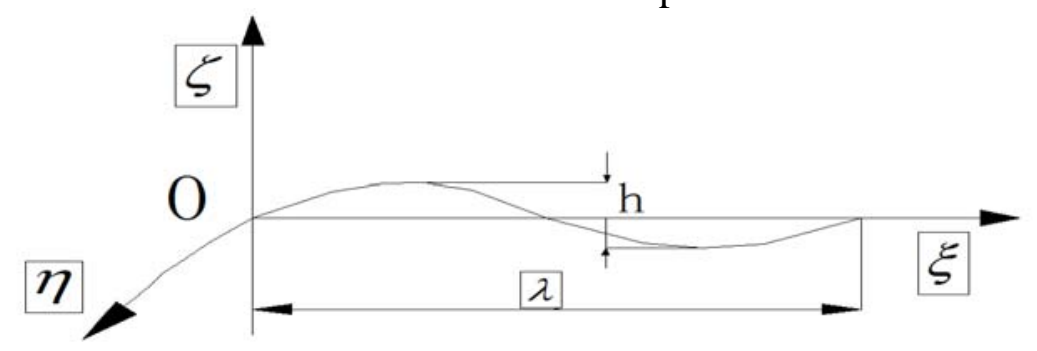

Figure 2 along the direction of movement of the rules of Porto

The pressure expression in the regular wave flow field is as follows:

$$
\Delta P=-\rho \frac{\partial \varphi}{\partial t}-\frac{1}{2} \rho\left(u^{2}+v^{2}+\omega^{2}\right)-\rho g \xi
$$

In this formula : $\rho \frac{\partial \varphi}{\partial t}$ represent the buoyancy of the hull, $\frac{1}{2} \rho\left(u^{2}+v^{2}+\omega^{2}\right)$ and $\rho g \zeta$ represent the pressure generated by the wave disturbance. The ship on the voyage, the hull will do motions with six degrees of freedom in addition to forward speed. Select a ship motion coordinate system, setting the positive $\mathrm{X}$ axis for the bow direction, the positive $\mathrm{Y}$ axis as the ship left, $\mathrm{Z}$ axis upward. The origin point set in the intersection in stern with the bottom line. The angle between Wave direction and $X$ axis is $\beta$, When the ship sails in the sea in facing the wave: $\beta=180^{\circ}$. At any moment, setting the coordinates in the instantaneous equilibrium position, the expressions of pressure of fluctuations in Fu Rude - Krylov hypothesis conditions as follows:

$\Delta P=\rho g a e^{\kappa z} \cos \left(\kappa x \cos \chi-k y \sin \chi-\omega_{e} t\right)$

The integration of dynamic pressure of wave in the wetted hull surface, expressed as a role in the wave disturbing force and moment:

$$
\begin{aligned}
& F_{W}=-\iint_{s} \Delta P n d S \\
& M_{W}=-\iint_{s} \Delta P(r \times n) d S
\end{aligned}
$$

In the formula, $\mathrm{s}$ - ship wet surface area; $\mathrm{n}$ - the unit normal vector of $\mathrm{s}$, the direction to the hull exterior ; $r$ - the spot of dynamic pressure relative to the position vector with coordinates of the ship. 


\subsection{To determine the wave parameters}

When calculating the deformation of the hull, generally choose the largest wave bending moment state to study, in order to ensure the safety of ship navigation, according to statistics [5-7], under the wavelength equal to the captain, wave bending moment reached the maximum. Therefore, it is the research object of this thesis, take the wave length $\lambda=320 \mathrm{~m}$, according to the conversion formula: $\omega=2 \pi / 0.8 \sqrt{\lambda}$ get the wave frequency :0.4.

In addition, according to the sea wave data shows that the frequent sea conditions in the waters of the sea are three to five stage waves. the wave above the six level is less. According to the provisions of Chinese oceanic's wave level, five stage wave: $2.5 \leq H_{1 / 3} \leq 4.0$,six stage wave: ${ }^{4.0} \leq H_{1 / 3} \leq 6.0, H_{1 / 3}$ as the significant wave height. So take the Common height: $\mathrm{H}=4 \mathrm{~m}$ and extreme condition of height $: \mathrm{H}=6 \mathrm{~m}$ as study wave height. Wave flow direction is -180 degrees. Therefore, The calculation equation can be drawn along the $\mathrm{X}$ direction with the spatial variation:

$\eta=4 \cdot \cos (x \cdot 160 / \pi+\varphi)$

Wave force can be calculated when ship at different wave phase angles, choose phase of calculation every 30 degrees from 0 degree to 360 degrees, a total of 12 different phase, resulting in the hull deformation of different phase. As a result, the wave calculation parameters such as table 1 shows:

Table 1 wave parameter table

\begin{tabular}{cccccc}
\hline Wave parameters & wave height $(\mathrm{m})$ & wavelength $(\mathrm{m})$ & frequency $(\mathrm{Hz})$ & phase $\left({ }^{\circ}\right)$ & Wave direction \\
\hline condition 1 & 4 & 320 & 0.4 & $0 \sim 360$ & Head sea \\
condition 2 & 6 & 320 & 0.4 & $0 \sim 360$ & Head sea \\
\hline
\end{tabular}

\section{Calculation results and data extraction}

\subsection{Results of ship deformation under hydrostatic condition}

Only loading hydrostatic pressure and the ship loading pressure on ship model, open the inertia releasing to calculate the hull deformation [8] and obtained the hull deformation under the hydrostatic state, results as shown in Figure 3, the ship shafting bearings from the exit of propeller shaft are sequentially numbered 1\#, 2\#, 3\#, 4\#, 5\#, 6\#, 7\#, 8\#, 9\#, 10\#, 11 \#, the bearing displacement as shown in Figure 3.
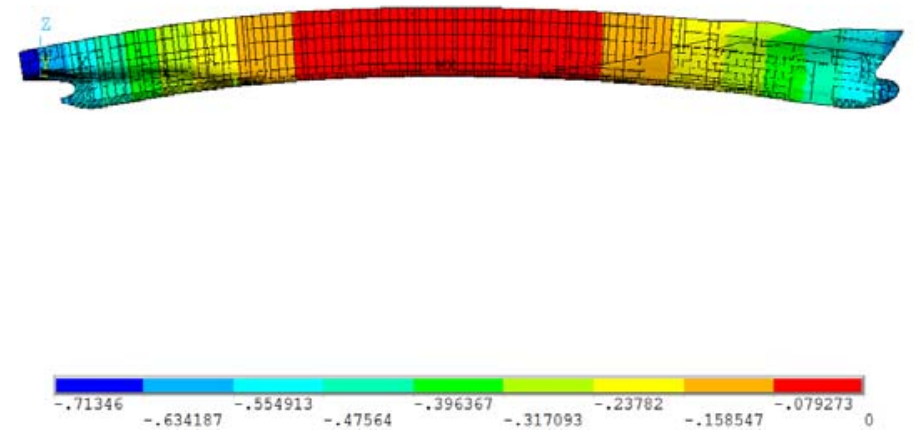

Fig. 3 vertical deformation of ship in still water 


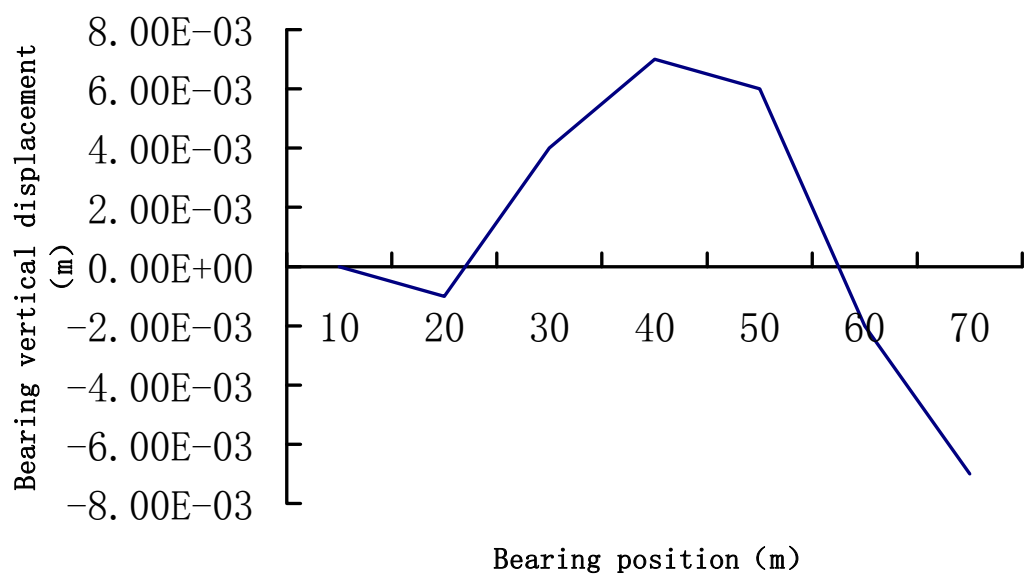

Fig4 Hydrostatic shaft system in vertical bitmap

According to figure 4 shows that when the ship is sailing in the static sea, the shaft will be a slightly curved, and then a large arch deformation, the largest deformation is located in the $5 \#$ and $6 \#$ bearings, the relative deformation is $7.2 \mathrm{~mm}$.

\subsection{Results of ship deformation under wave loads}

Exerting cargo pressure, hydrostatic pressure and wave dynamic pressure load on container ship, Then release a spot on boat as the inertia constraint, calculating the hull deformation under the condition of full load, extracting the vertical displacement of the 11 bearings' position, put the displacement of the bearings at the end of the stern shaft and the bulkhead of the engine room as the reference.The displacements of shaft in 12 kinds phases of waves ( $4 \mathrm{~m}$ and $6 \mathrm{~m}$ wave height) as be calculated in following figures.

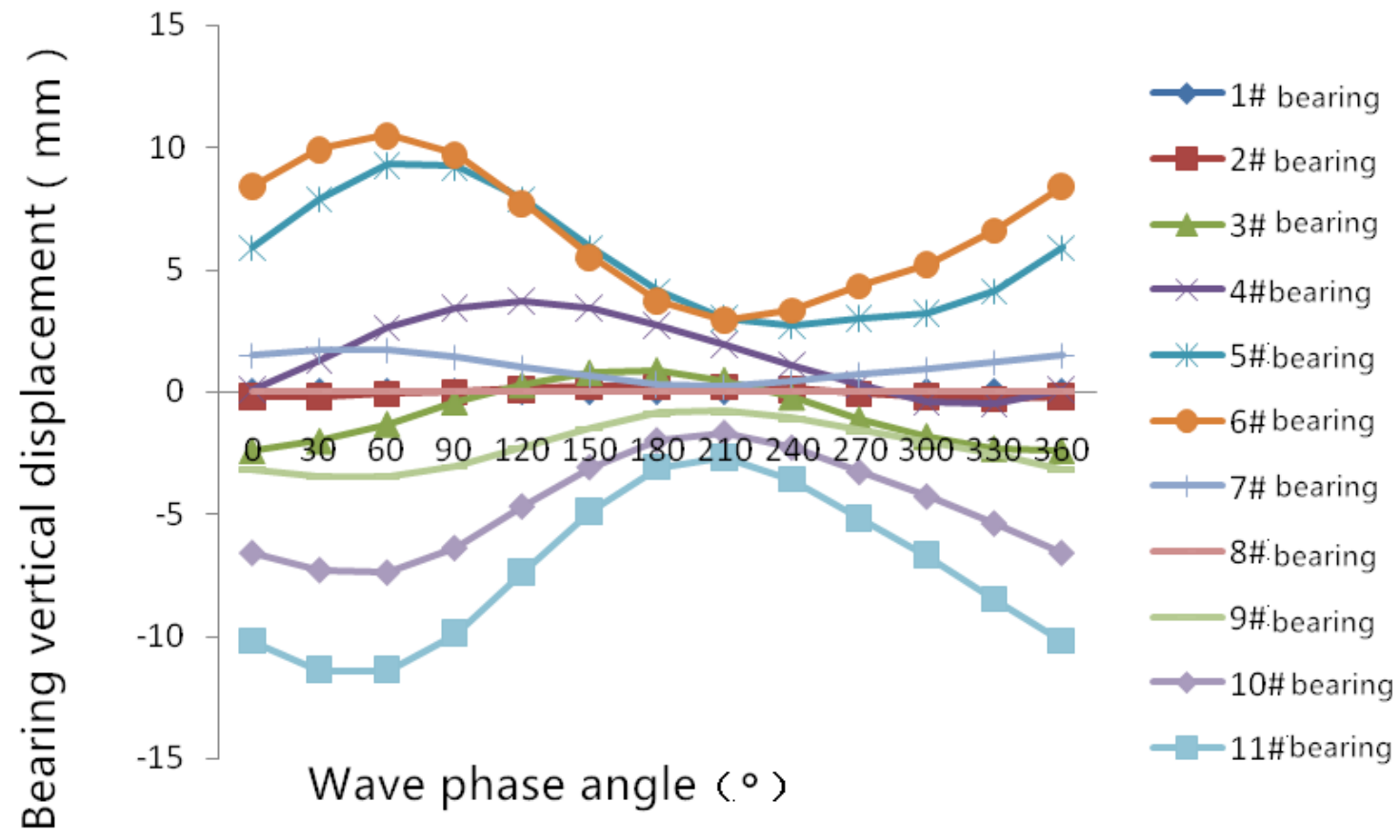

Fig. 5 the deformation of the bearings under different phase waves (4m) 


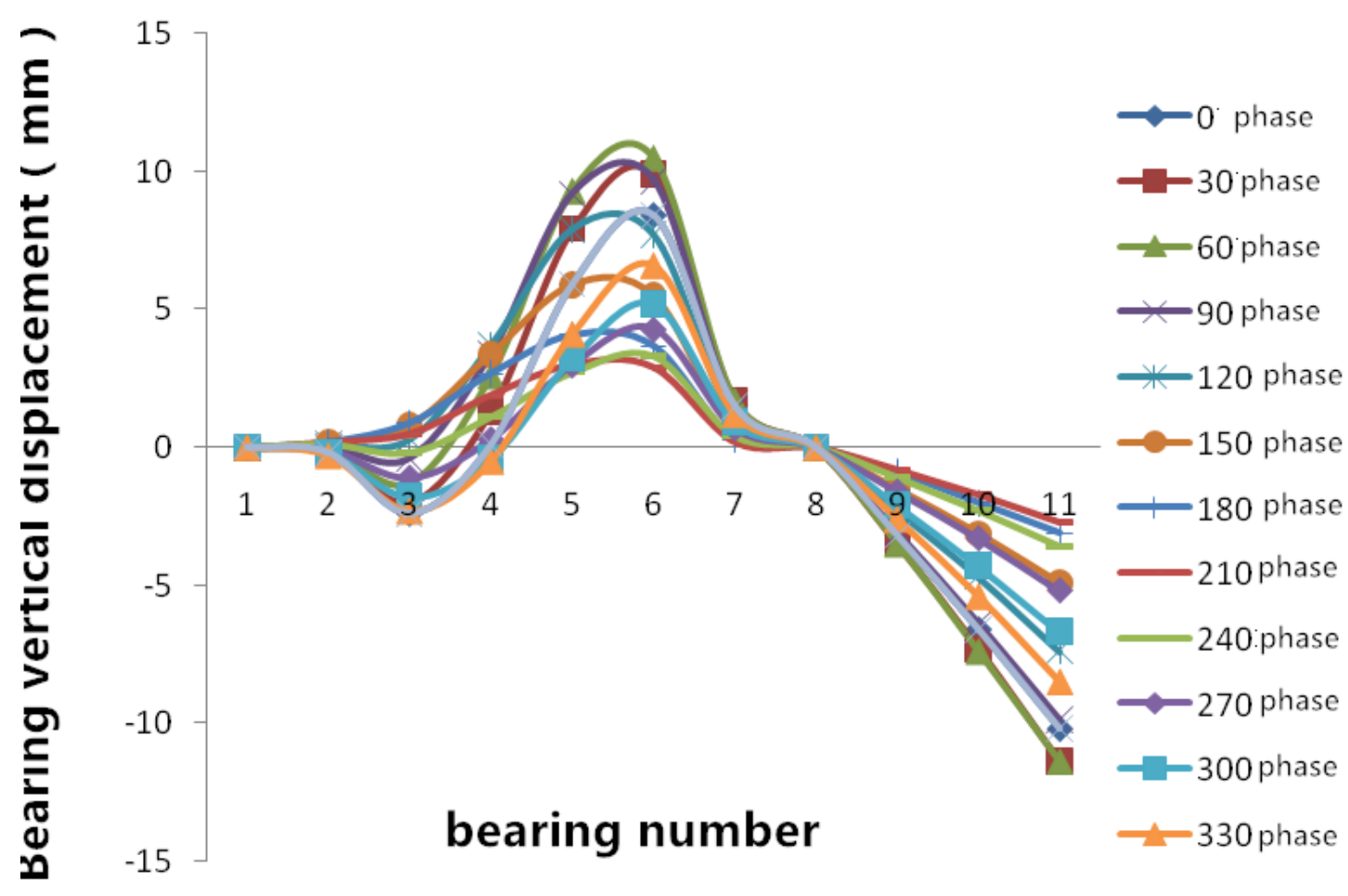

Fig.6 relative deformation of the bearings under each phases (4m)

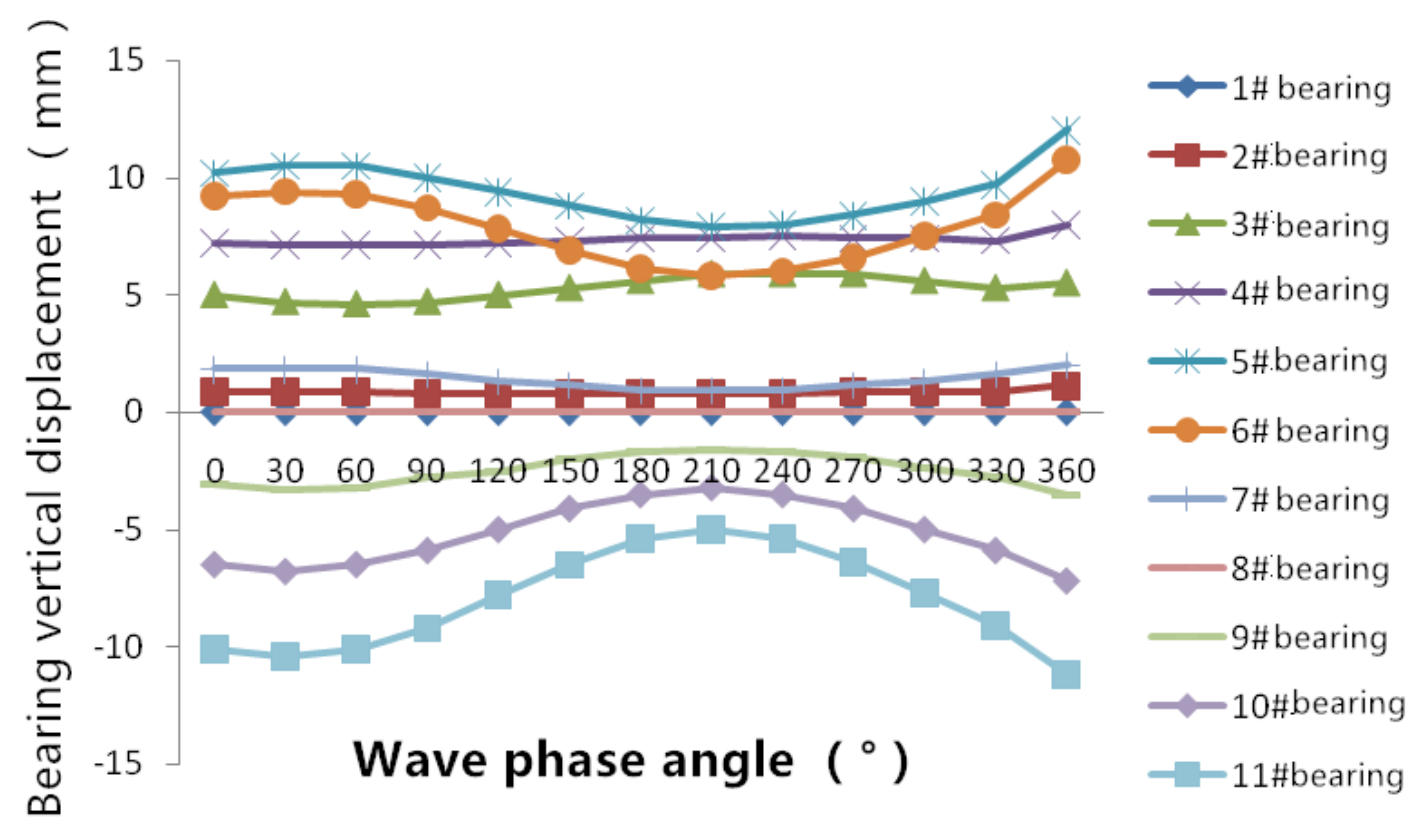

Fig. 7 the deformation of the bearings under different phases $(6 \mathrm{~m})$ 


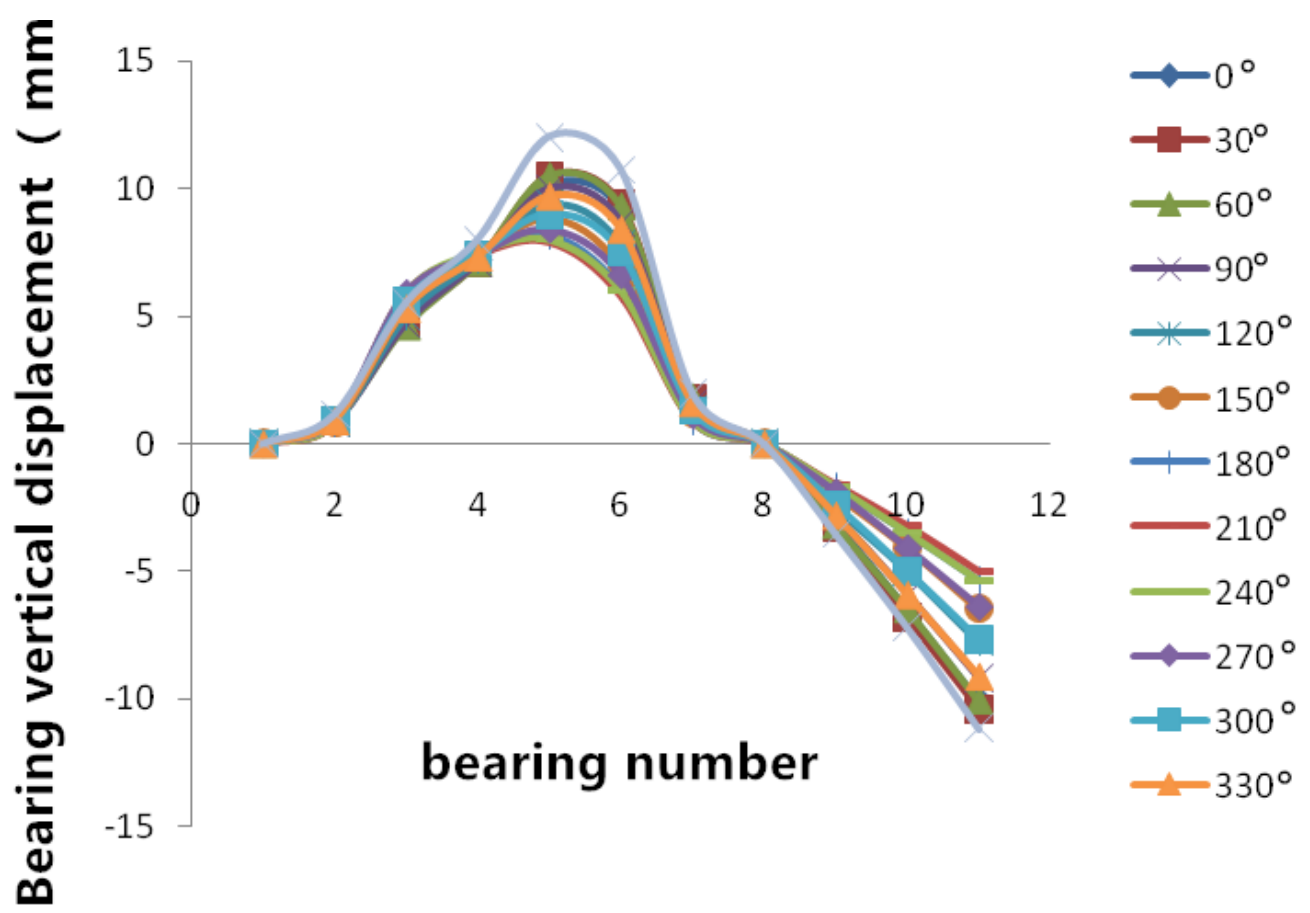

Fig. 8 relative deformation of the bearings under each phases $(6 \mathrm{~m})$

From Figure 5 and Figure 7 can be seen, the vertical displacement of ship shafting is sine curve along with the wave phases' changing, and each frequency values of fitting function the same as the waves, but datum value, wave peak value and phase value of vertical displacement of each bearings. Figure 6 shows the deformation trend of shafting center line due to hull deformation, using $1 \#$ and 8\# as the benchmark ,the relative displacement of $2 \#$ and $7 \#$ bearings are small,but the $6 \#$ and 11\# bearings largest ,the relative deformation of the shafting center line is "convex" form; under the condition of full load,the relative deformation of the maximum is $10.9 \mathrm{~mm}$ in the action of $4 \mathrm{~m}$ wave, and the $6 \mathrm{~m}$ wave is $12.4 \mathrm{~mm}$ in the thrust bearing of the host behind .which reflects that the host stiffness on the effects of hull deformation, also shows that the full operation conditions is the main effects on the shafting; the deformation is most obvious in the 30。 phase angle and 60 。 phase angle under wave load, the relative deformation is the minimum in the 210。 phase angle and 240 。 phase angle, shaft displacement curve is smooth. From Figure 5 and Figure 7 can be seen, The shafting is obviously raised under $6 \mathrm{~m}$ wave heights with respect to $4 \mathrm{~m}$ height.

\section{4 conclusion}

In this paper, the deformation of the hull is calculated and analyzed. The law of the deformation of the hull under wave load is analyzed, and the research of this paper is summarized as follows;

(1)using the finite element programming method and APDL language loading procedure to apply load on ship automatically,using the handle boundary conditions of inertia release to derive the hull deformation under the different conditions. The vertical displacement data of double deck under different working conditions were analyzed and compared with the static water condition, the deformation of ship hull under the action of wave is obvious..

(2) the propulsion shafting running state is not the same under different wave loading conditions,hull deformation data can be extracted as the basis of analysising shafting condition in different wave conditions, and then analyzes the influence of wave load on the propulsion shafting..

(3) The deformation of the hull is different from the phase of the wave in the same condition, the hull deformation showed a sinusoidal changing along with the transition of wave phase, the shafting is obviously raised under $6 \mathrm{~m}$ wave heights with respect to $4 \mathrm{~m}$ height. 


\section{Reference}

[1] Dong Hengjian. Research on the influence of Ship Deformation on shafting system [J]. ship engineering, 2009 (2): 8-11

[2] Shi Lei. Study on the calculation of hull deformation in shafting alignment [J]. ship engineering, 2010 (3): 13-16

[3] Zhu Yunzhao. Influence of Ship deformation on pose parameters and its measurement[J].micro computer information, 2008 (8): 285-287.

[4] Zhu Yunzhao. The Review of Ship Deformation Measurement Technique [J]. ship engineering, 2007 (6): 58-61.

[5] Wu Tan. The deformation and stress analysis of the bearing point of the propulsion shafting of large container ship [D]. Wuhan University of Technology 2013

[6] Tang forces. Large container ship 3D wave load computation [D]. Wuhan University of Technology 2008

[7] He Lizi.Dynamic response analysis of super large ships in waves [D]. Wuhan University of Technology 2013

[8] Li Lijuan. Estimation of hull deformation by the method of inertia matching [D]. Wuhan University of Technology 2009 